\title{
INVESTIGANDO AS IMPLICAÇÕES DOS PROCESSOS INTERATIVOS E AVALIATIVOS, AS APRENDIZAGENS/NÃO-APRENDIZAGENS NO DESEMPENHO ACADÊMICO DE JOVENS NA EDUCAÇÃO SUPERIOR: UMA REVISÃO
}

\author{
INVESTIGATING THE IMPLICATIONS OF INTERACTIVE AND EVALUATING \\ PROCESSES, LEARNING / NON-LEARNING IN YOUTH'S ACADEMIC \\ PERFORMANCE IN HIGHER EDUCATION: A REVIEW
}

\section{Danielle Alessandra Souza de Holanda Cavalcanti ${ }^{1}$ Islane Cristina Martins ${ }^{2}$}

RESUMO: Introdução: As dificuldades vivenciadas por estudantes universitários no campo das interações, aprendizagens/não-aprendizagens e avaliação durante a graduação, podem interferir seu desempenho acadêmico, dificultando ou favorecendo o aprendizado destes discentes. Objetivo: Realizar uma revisão integrativa da literatura a fim de compreender as implicações dos processos interativos e avaliativos, as aprendizagens/não-aprendizagens no desempenho acadêmico de jovens na educação superior. Materiais e Métodos: Foi feita uma busca das referências nas bases Periódicos CAPES e Google Scholar em março de 2020. A busca permitiu a identificação de 4 artigos que se adequaram aos critérios estabelecidos. Resultados: Foi possível observar que 50\% dos artigos apontam que a avaliação ainda é temática contraditória, mas com variações, objetivos e instrumentos que podem favorecer discentes. Da totalidade, $25 \%$ apontam que os docentes acreditam na avaliação formativa como processo justo para os estudantes e os outros $25 \%$ afirmam que o uso de tecnologia favorece os espaços de aprendizagem e as relações neles estabelecidas. Conclusão: Os artigos apontam que o desempenho acadêmico de estudantes universitários está diretamente relacionado ao bom ou mau exercício das atividades desenvolvidas durante o percurso da vida discente no ensino superior.

Palavras-chave: Ensino Superior, Estudante universitário, Avaliação, Desempenho acadêmico, Tecnologia.

ABSTRACT: Introduction: The difficulties experienced by undergraduate students in the field of interactions, learnings/non-learnings and assessment during higher education can interfere with their academic performance, and impair or promote their learning outcomes. Objective: Perform an integrative revision of the literature in order to better understand the repercussion of interactive and appraisal processes, learning, and non-learning outcomes on

1 E- mail: Graduada em psicóloga pela Universidade Federal de Pernambuco- UFPE. Servidora da Secretaria Municipal de Educação, Esportes e Cultura da cidade de Escada-PE. E-mail: danisouzahcavalcanti@gmail.com.

${ }^{2}$ Biomédica pela Universidade Federal de Pernambuco-PE, mestre em Neurociências pelo Programa de Pós-Graduação em Neuropsiquiatria e Ciências do Comportamento - UFPE e doutoranda pelo PPGBAS LIKA-UFPE. Professional and Self Coach - IBC. E-mail: islanemartins@gmail.com. 
the academic achievement of young people in higher education. Materials and methods: In March 2020, an online search for articles was made on CAPES portal for periodic publications and on Scholar Google. It was identified 4 articles that were in accordance with the criteria set up. Results: It was observed that $50 \%$ of the studies showed that the assessment is a contradictory subject, but with variations, objectives and instruments that can help students. $25 \%$ of studies point out that lecturers believe in the formative assessment as a fair process to students, while $25 \%$ state that the use of technology promotes the learning environment and the relationship established in the environment. Conclusion: Studies show that the academic performance of university students is directly related to well or poor of activities carried out during higher education.

Keywords: Higher education, University student, Assessment, Academic Performance, Technology.

\section{INTRODUÇÃO}

Ao longo dos anos a educação superior vem sofrendo mudanças consideráveis, sejam estas relacionadas às suas normas, valores, ampliação e diversidade, sejam dados os diversos tipos de instituições, cursos e do papel social do ensino (Sousa, Almeida, Bard e Cancela, 2018).

No Brasil, o ensino superior não é homogêneo, sendo organizado de diferentes formas e a partir de diversas culturas, não tendo uma única identidade e se convertendo constantemente (Severino, 2008).

Um exemplo disso é a reestruturação curricular, a qual denota a necessidade de o professor dessas instituições incluir em sua prática pedagógica questões socioculturais através de atividades que valorizem o contexto do aluno e sua bagagem de conhecimentos prévios (Moura, 2017).

Além disso, a reestruturação curricular pressupõe também a formação de professores, esta correspondendo a um processo que ocorre continuamente durante toda a vida profissional do docente (Moura, 2017).

Bem como, sendo atividades desenvolvidas e oportunizadas pelas próprias instituições às quais estes profissionais estão vinculados, seja pelo sistema ou por iniciativa própria do professor (Araújo, Silva e Silva, 2019).

Todavia, os processos avaliativos que se dão na educação superior ainda são marcados pelo viés tradicionalista e com práticas voltadas à classificação/categorização do estudante, a partir do seu desempenho e resultados (Sousa, Almeida, Bard e Cancela, 2018).

Não só isso, mas estão também os processos interativos estabelecidos neste contexto, os quais - haja vista estarem imersos em uma realidade influenciada pelos avanços científicos e tecnológicos - necessariamente precisam ser ressignificados diante das transformações socioculturais, e de novas formas de construção do conhecimento (Cerutti e Melo, 2017). 
Nesse sentido, as aprendizagens na educação superior ocorrem num contexto imerso em avanços tecnológicos e que gritam por novas formas e olhares de seus protagonistas, professores e estudantes, abrindo perspectivas metodológicas que garantam a aprendizagem e o ensino de qualidade (Cerutti e Melo, 2017).

Não só isso, mas, negar essa nova realidade ou não se adaptar a ela seria contribuir para as não-aprendizagens quando a necessidade da figura do docente enquanto mediador do processo de aprendizado é fundamental (Cerutti e Melo, 2017).

Dito isso, é necessário compreender que as instituições de ensino superior são compostas hoje por discentes imersos num contexto tecnológico e que através deste exprimem desejos e sapiência, tendo a tecnologia como colaboradora (Cerutti e Melo, 2017).

Por isso, o objetivo do presente estudo foi realizar uma revisão integrativa da literatura a fim de compreender as implicações dos processos interativos e avaliativos, as aprendizagens/não-aprendizagens no desempenho acadêmico de jovens na educação superior a partir da identificação das maiores dificuldades vivenciadas por estudantes no campo das interações e avaliações durante o período de sua graduação, bem como verificar de que forma se dão esses processos de modo a favorecer ou dificultar a aprendizagem e o desempenho acadêmico de discentes universitários.

\section{MATERIAIS E MÉTODOS}

Foi feito um levantamento da literatura em março de 2020, nas bases de dados Periódicos CAPES e Google Acadêmico. Os descritores utilizados foram os seguintes: "Concepção docente" AND "Formação de Professores" AND "Necessidades Formativas" AND "Reestruturação Curricular" AND "Educação Superior" e "Teacher Conception" AND 'Teacher Training” AND "Training Needs" AND 'Curricular Restructuring” AND "Hihger Education" em ambas as bases de dados. Foram selecionados 04 artigos sendo incluídos segundo os critérios de elegibilidade conforme a Figura I. Os critérios de inclusão foram: artigos nos idiomas inglês, espanhol e português, nos últimos cinco anos, envolvendo as implicações dos processos interativos e avaliativos, as aprendizagens/não-aprendizagens no desempenho acadêmico de jovens na educação superior. Os critérios de exclusão foram artigos de revisão de literatura. 
FIGURA r. FLUXOGRAMA E CRITÉRIOS DE SELEÇÃO E INCLUSÃO DOS ARTIGOS

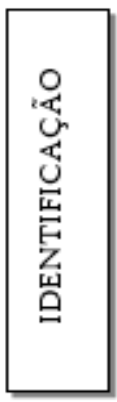

ARTIGOS ENCONTRADOS NAS BASES DE DADOS DOS

PERIÓDICOS CAPES E GOOGLE ACADÊMICO $(\mathrm{N}=32.756)$

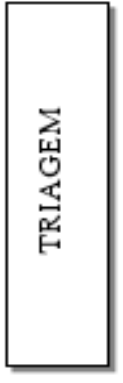

ESTUDOS EXCLUÍDOS PELO TÍTULO $(\mathrm{N}=32.706)$

\begin{tabular}{|l|}
\hline \\
㟧 \\
号 \\
㟔 \\
岃 \\
岃 \\
\hline
\end{tabular}

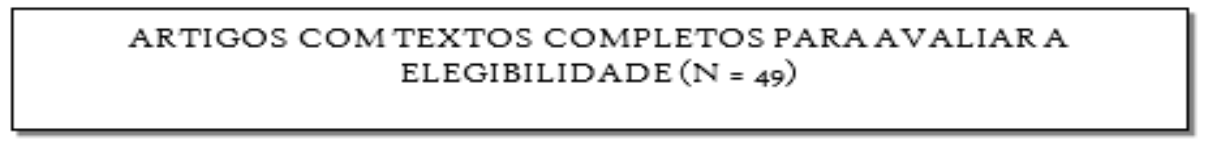

ESTUDOS DUPLICADOSREMOVIDOS $(\mathrm{N}=0 \mathrm{r})$
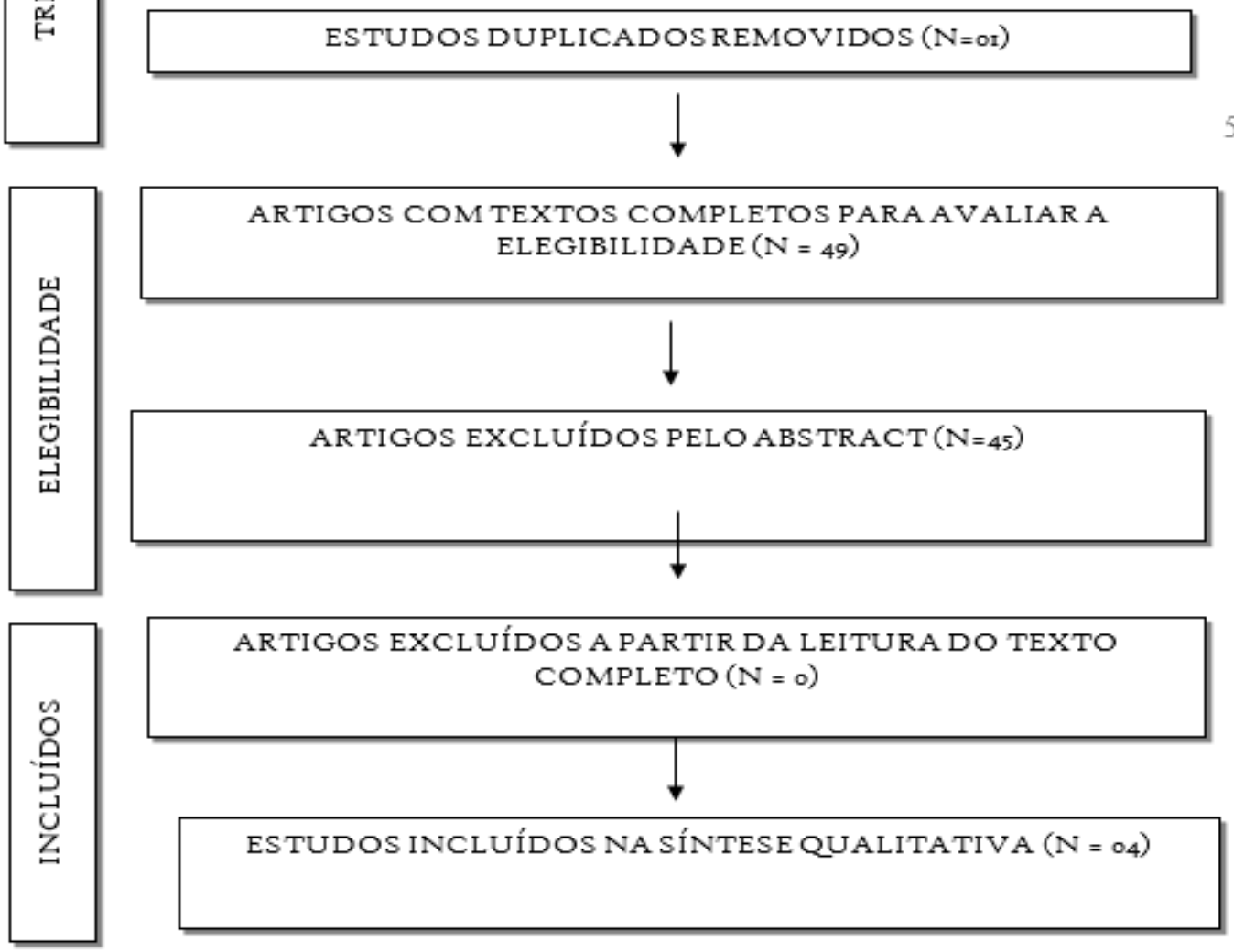

Fonte: autoras

\section{RESULTADOS}

Os resultados do presente estudo encontram-se na Tabela I. 
Revista Ibero- Americana de Humanidades, Ciências e Educação- REASE

Tabela I - Demonstrativo dos artigos que integram a Revisão Integrativa

\begin{tabular}{|c|c|c|c|c|c|c|}
\hline$\# \mathrm{~N}$ & Data & Título & Autores & Periódico & Objetivos & Resultados \\
\hline I & 2017 & $\begin{array}{l}\text { Avaliação do } \\
\text { ensino: } \\
\text { aprendizagem na } \\
\text { percepção de } \\
\text { discentes e docentes } \\
\text { no curso de letras da } \\
\text { Universidade } \\
\text { Estadual Vale do } \\
\text { Acaraú (UVA) }\end{array}$ & $\begin{array}{l}\text { Neudiane } \\
\text { Moreira Félix, } \\
\text { Evaneide } \\
\text { Dourado } \\
\text { Martins }\end{array}$ & $\begin{array}{l}\text { Revista on-line de } \\
\text { políticas e Gestão } \\
\text { Educacional }\end{array}$ & $\begin{array}{l}\text { Compreender a percepção de } \\
\text { discentes e docentes sobre a } \\
\text { avaliação do ensino-aprendizagem } \\
\text { no curso de Letras da Universidade } \\
\text { Estadual Vale do Acaraú -UVA. }\end{array}$ & $\begin{array}{l}\text { Foi descoberto que I) a avaliação ainda é um tema cercado de mitos e impasses, que apresenta } \\
\text { desafios conceituais, procedimentais e atitudinais; } 2 \text { ) a avaliação possui finalidades, funções, } \\
\text { tipos e instrumentos avaliativos que poderão facilitar a vida dos docentes e dos estudantes, se } \\
\text { forem reconhecidos e utilizados corretamente pelos mesmos em sala de aula; } 3 \text { ) aplicar uma } \\
\text { avaliação em sala de aula é um caminho de mão dupla, pois produzirá resultados para os } \\
\text { docentes e discentes, exigindo uma análise processual das situaçôes que levaram a tais } \\
\text { resultados. }\end{array}$ \\
\hline 2 & 2017 & $\begin{array}{l}\text { Concepção dos } \\
\text { docentes e discentes } \\
\text { acerca do processo } \\
\text { avaliativo e o seu } \\
\text { papel } \\
\text { disciplinas } \\
\text { específicas no curso } \\
\text { de licenciatura em } \\
\text { matemática }\end{array}$ & $\begin{array}{l}\text { Gabriela } \\
\text { Tavares de } \\
\text { Moura }\end{array}$ & 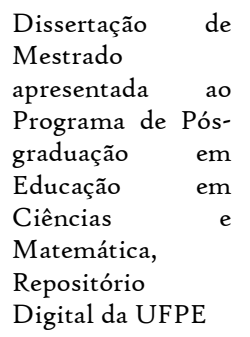 & $\begin{array}{l}\text { Discutir alguns princípios } \\
\text { norteadores de práticas avaliativas } \\
\text { processuais e formativas que } \\
\text { tendem acompanhar o o } \\
\text { desenvolvimento do aluno a partir } \\
\text { de discussões sobre a avaliação } \\
\text { praticada no Ensino Superior. }\end{array}$ & $\begin{array}{l}\text { Os discentes consideram que as aulas de matemática e a avaliação ainda acontecem de modo } \\
\text { tradicional, com extensas listas de exercícios que se baseiam em questões que irão cair na } \\
\text { prova, tornando os alunos meros reprodutores de fórmulas, inibindo por vezes, o estudante } \\
\text { desenvolver sua autonomia. }\end{array}$ \\
\hline 3 & 2016 & $\begin{array}{l}\text { Avaliação no } \\
\text { Ensino Superior e } \\
\text { qualidade } \text { da } \\
\text { aprendizagem: } \\
\text { percepções práticas } \\
\text { e implicações }\end{array}$ & $\begin{array}{l}\text { Diana } \\
\text { Alexandra } \\
\text { Ribeiro Pereira }\end{array}$ & $\begin{array}{l}\text { Tese de Doutorado } \\
\text { apresentada ao } \\
\text { Instituto } \quad \text { de } \\
\text { Educação } \\
\text { Universidade da } \\
\text { Minho - Portugal }\end{array}$ & $\begin{array}{l}\text { Compreender } \text { o modo como os } \\
\text { professores e os alunos } \\
\text { universitários percepcionam o } \\
\text { processo de avaliação e contribuir } \\
\text { para a melhoria da qualidade dos } \\
\text { processos de ensino, aprendizagem } \\
\text { e avaliação no ensino superior. }\end{array}$ & $\begin{array}{l}\text { Os resultados sugerem que uma mudança de paradigma de uma abordagem centrada no } \\
\text { professor para uma abordagem centrada no aluno é valorizada pelos professores } \\
\text { universitários. Particularmente, uma avaliação centrada no aluno é entendida como positiva, } \\
\text { uma vez que traz benefícios para o processo de aprendizagem. Para além disso, fomenta a } \\
\text { avaliação formativa e o feedback sendo considerada como um processo de avaliação mais } \\
\text { justo. }\end{array}$ \\
\hline 4 & 2016 & $\begin{array}{l}\text { Didática e Ensino } \\
\text { com acessibilidade e } \\
\text { afetividade no } \\
\text { Ensino Superior }\end{array}$ & $\begin{array}{l}\text { Olga Lucía Leon } \\
\text { Corredor, Dora } \\
\text { Inés Calderón, } \\
\text { Álvaro García- } \\
\text { Martínez, } \\
\text { Marcia Reis }\end{array}$ & $\begin{array}{lr}\text { Anais da } & 7^{\underline{a}} \\
\text { Conferência } & \\
\text { Internacional } & \\
\text { sobre } & \\
\text { Desenvolvimento } \\
\text { de Software e } \\
\text { Tecnologias ou } \\
\text { Melhorando r a } \\
\text { Acessibilidade } & \text { e } \\
\text { Combate } & \text { à } \\
\text { Exclusão } & \text { de } \\
\text { Informações } & \end{array}$ & 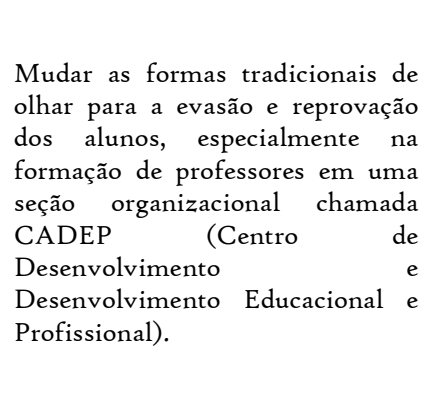 & $\begin{array}{l}\text { Espera-se que o Módulo Grow, que trabalha no CADEP, juntamente com os outros módulos, } \\
\text { ofereça às universidades da Europa e da ALC acesso a sistemas de informação sobre: as } \\
\text { relaçôes entre a diminuiçãa da deserção e a repetição de cursos, a caracterização do efeito da } \\
\text { afetividade social no conteúdo do ensino superior, as tendências didáticas e os tipos de } \\
\text { ambientes de aprendizagem nas universidades, o uso inovador das tecnologias e as formas de } \\
\text { cooperação solidária interna e externa. Também se espera que as universidades parceiras no } \\
\text { Chile, Peru, Brasil, Colômbia e Nicarágua formem equipes profissionais para criar, usar e } \\
\text { valorizar recursos, tecnologias, didática, ambientes de aprendizado e formas de cooperação } \\
\text { solidária em comunidades de prática. }\end{array}$ \\
\hline
\end{tabular}




\section{DISCUSSÃO}

O objetivo do presente estudo consiste em apresentar uma revisão de artigos que abordam a problemática da avaliação dentro do processo de ensino-aprendizagem de estudantes universitários, e o impacto desta no desempenho e nas relações estabelecidas por eles no contexto acadêmico.

Observou-se que pensar sobre o processo de avaliação é algo extremamente necessário, haja vista a necessidade de que ele seja efetivado de forma acessível e adequada (Moura, 2017).

Isto é, a reflexão sobre a prática avaliativa é algo imprescindível para que o corpo docente possa ajudar de forma efetiva seus discentes quanto ao seu desenvolvimento (Moura, 2017).

Não só isso, mas avaliar se o desenvolvimento dos estudantes está em consonância com aquilo que foi planejado enquanto perspectiva da disciplina proposta pelo professor alcançar (Moura, 2017).

Desse modo, faz-se necessária uma mudança quanto ao olhar tradicional sobre a avaliação e questões como a não aprovação de estudantes, o abandono do curso em andamento, assim como também com relação às estratégias de intervenção a serem usadas para minimizar e/ou solucionar este problema (Félix \& Martins, 2017).

Nesse sentido, diante da crescente universalização do acesso ao conhecimento a partir dos meios de comunicação e tecnologia, a prática educativa sofre influência e influencia o processo de ressignificação da avaliação de estudantes, já que o professor nesta nova conjectura social não é mais a figura exclusiva a possuir o saber (Félix \& Martins, 2017).

Todavia, essa releitura e ressignificação do processo de ensino-aprendizagem e de avaliação no ensino superior ainda não é absoluta e traz alguns questionamentos, o que é percebido pelo uso ainda prevalente de estratégias avaliativas tradicionais, como as provas objetivas (Félix \& Martins, 2017).

Isso se deve ao fato de, conforme proposto por Félix e Martins (2017), ser notório que uma parcela considerável de unidades de ensino, seja de nível básico ou superior, não obstante suas propostas transformadoras de prática pedagógica, ainda favorecer a Pedagogia Tradicional.

Esse fenômeno pode acontecer devido a indiscutível questão que aponta que os docentes são estimulados a repassarem avaliações tradicionais, reiterativas e "decorativas" dos assuntos expostos em classe, o que culmina na facilidade de manutenção da burocracia dos estabelecimentos de ensino (Félix e Martins, 2017). 
Nesse sentido, os estudos apontam ainda para uma mudança de paradigma do foco no professor para um enfoque na perspectiva do estudante onde a elaboração do método pedagógico no processo de formação de novos profissionais, no contexto contemporâneo e globalizado, não deve se resumir unicamente ao repasse de saberes, já que a aprendizagem se faz de forma dinâmica com o ensino (Leon, Calderon, e Garcia-Martinez, 2016).

Não só isso, mas é perceptível que a problemática pedagógica vai além da transmissão do conhecimento de forma organizada e sistemática, numa relação entre passado e o presente, mas diz respeito ao processo formativo da juventude acadêmica para um futuro não ortodoxo, e sim aberto a construções coletivas, partilhadas horizontalmente entre docentes e discentes (Pereira, 2016 como citado em Sursock e Smidt, 2010; Asikainem, Virtanen, Postareff e Heina, 2014; Lea, Stehenson e Tray, 2013 Attard, et al 2010).

Dito isso, faz-se necessária uma análise da relação de disciplinas contidas nas grades curriculares de cursos de graduação a nível superior e sua conexão com os números de reprovações e/ou abandono dos cursos por parte dos estudantes (Pereira, 2016 como citado em Fiorentin et al 1998, p.316).

Não só isso, mas apontar ainda para uma imersão na estrutura curricular dos cursos de graduação, bem como também, compreender a relação deste curso com elementos sócioculturais, visando com isso uma maior aproximação com a realidade do estudante (Pereira, 2016 como citado em Fiorentin et al, 1998, p.316).

Desse modo, percebe-se a necessidade do professor revisitar sua prática a partir daquilo que tem como objetivo que seu trabalho de ensinar alcance: se este se resume a transmissão de conteúdo ou, por outro lado, que o seu corpo discente se aproprie do conhecimento, entenda e compreenda (Pereira, 2016 como citado em Huba e Fred, 2000).

Nesse sentido, entre outras implicações relacionadas ao processo avaliativo de discentes de cursos superiores está a função, muitas vezes implícita atrelada à avaliação, relacionada ao controle comportamental de estudantes e/ou punição (Moura, 2017).

Outro aspecto que também precisa ser levado em consideração é o caráter motivacional atrelado à dinâmica ensino-aprendizagem e à avaliação que, segundo Viana (2003), ambos interferem e são afetados mutuamente. Além da motivação dos discentes interferir diretamente na prática avaliativa (Viana, 2003, p.46).

\section{CONCLUSÃO}

O objetivo do presente estudo foi apresentar uma revisão de artigos que abordassem a problemática da avaliação dentro do processo de ensino-aprendizagem de estudantes 
universitários e o impacto desta no desempenho e nas relações estabelecidas por eles no contexto acadêmico.

O processo avaliativo no ensino superior apresenta muitos desafios, tais quais as questões históricas que o permeiam, com métodos tradicionais de avaliação centralizados no professor sendo ainda muito comuns no contexto universitário.

Um exemplo disso é a existência de avaliação de caráter métrico e classificatório dos estudantes, que ainda ocorre de forma significativa nas universidades.

Nesse sentido, percebe-se uma mudança de perspectiva na educação contemporânea onde a avaliação vem sendo concebida como processo/prática complementar ao ensino e consequentemente à aprendizagem.

Tal fenômeno acontece dessa forma a partir da compreensão de que a aprendizagem não ocorre de forma isolada ao ensino - mas processual e abrangendo aspectos socioculturais e afetivos -, não estando reduzida apenas a um resultado quantitativo e classificatório (nota), estando diretamente relacionada com a motivação de estudantes e professores.

Portanto, as implicações dos processos interativos e avaliativos, as aprendizagens/não-aprendizagens no desempenho acadêmico de jovens na educação superior estão diretamente relacionadas ao bom ou mau exercício das atividades desenvolvidas durante o percurso da vida discente no ensino superior. O estudante não é uma peça isolada da universidade; relaciona-se com ela e com outros atores (tais quais docentes e comunidade acadêmica como um todo), e ainda com seus próprios desafios pessoais, de ordem afetiva, sociocultural e econômica. O discente segue, durante o ensino superior, uma caminhada ascendente, descendente ou estagnante, a depender do quão motivadora e impactante esta venha a ser, e que pode ser definidora do seu sucesso ou fracasso acadêmico.

\section{REFERÊNCIAS}

ARAÚJO, RMB; SILVA, M.D; SILVA, M.C. A formação continuada de professores da educação básica: concepções e desafios na perspectiva dos docentes. Revista @mbienteeducação. São Paulo: Universidade Cidade de São Paulo, v. 12, n. 3, p. 17-38 set/dez 2019.

CERUTTI, Elisabete; MELO, Fernandes de. Abordagem híbrida no Ensino Superior: reflexões teórico-metodológicas. RPGE- Revista on line de Política e Gestão Educacional, $\begin{array}{lllllll}\text { v.21, n. } & \text { esp. } & \text { p. } & \text { po5-620, } 2016 . & \text { out. } / 2017 . & \text { DOI }\end{array}$ http://dx.doi.org/10.22633/rpge.v21.n.espi.out.2017.9826.

CORREDOR, Olga; CALDERÓN, Dora; MARTÍNEZ, Álvaro; REIS, Márcia. Didactics and teaching with accessibility and affectivity in higher education. 99-104. Io.1145/3019943.3019958. 
CUNHA, Maria Isabel da. O tema da formação de professores: trajetórias e tendências do campo na pesquisa e na ação. Universidade do Vale do Rio dos Sinos, São Leopoldo, RS. Educ. Pesqui., São Paulo, Ahead of print, 2013.

FELIX, Neudiane Moreira; MARTINS, Evaneide Dourado. Avaliação do ensinoaprendizagem na percepção de discentes e docentes no curso de Letras da Universidade Estadual Vale do Acaraú. Revista on line de Política e Gestão Educacional, Araraquara, v.2I, n.2, p. 502-521, maio-ago. 2017. Disponível em: 〈http://dx.doi.org/10.22633/rpge.v21.n.2.2017.9976〉. ISSN: 1519-9029.

FIORENTTINI, D. A formação matemática e didático-pedagógica nas disciplinas da licenciatura em matemática. Revista da Educação. PUC-Campinas, Campinas, n.18, p. I07-115, junho, 2005.

HUBA, M.E; FRED, J. Learner centered Assessment on College Campuses: Shifting the Focus fromTeaching to Learning. Boston, MA: Allyn and Bacon, 2000.

MARTINS, Natalia; MORAES, Dirce Aparecida Foletto; SANTOS, Adriana Regina de Jesus e (2014). Concepção docente: a prática pedagógica em questão. III Jornada de didática: desafios para a docência e II Seminário de Pesquisa do CEMAD, Paraná.

MOURA, Gabriela Tavares de (2017). Concepções dos docentes e discentes acerca do processo avaliativo e o seu papel nas disciplinas específicas no curso de licenciatura em matemática. Dissertação (Mestrado em Educação em Ciências e Matemática) - PPGECM, Universidade Federal de Pernambuco, Caruaru.

PASSALACQUA, Flávia Graziela Moreira (2017). Necessidades formativas: os impasses para a efetividade das ações de formação continuada de professores no espaço escolar. $226 \mathrm{f}$. Tese (Doutorado em Educação Escolar) - UNESP, Faculdade de Ciências e Letras, - Campus de Araraquara.

PRADO, Iara Glória. O MEC e a reorganização curricular. Areias, 2000.

RODRIGUES, A; ESTEVES, M. A análise de necessidade na formação de professores. Portugal. Porto Editora, 1993.

SEVERINO, Antonio e Joaquim. O ensino superior brasileiro: novas configurações e velhos desafios. Editora UFPR, Educar, Curitiba, N. 31, P. 73-89, 2008.

SOUSA, Luciano Dias de; ALMEIDA, Flávio Aparecido de; BARD, Lucimere Aleixo; CANCELA, Lucas BORCARD (2018). Os desafios enfrentados pelos professores no processo de avaliação no ensino superior. Regae-Revista de Gestão e Avaliação Educacional; vol. 7, Núm. 16, setembro-Dezembro, pp. 59-66.

SURSOCK, A., SMIDT, H. Trends 2010: a decade of change in European higher Education. Belgium: EUA Publications, 2010.

VIANNA, H. M. Avaliações Nacionais em Larga Escala: análise e propostas. In: Estudos em Avaliação Educacional, n. 27, jan-jun/ 2003. 